\title{
Procesos espaciales, HABITAR E IMAGINARIOS EN LOS ESPACIOS URBANOS DE CiUdad JuÁREZ
}

RAMÓN LEOPOLDO MORENO MURRIETA ${ }^{1}$

\section{RESUMEN}

4 n la actualidad el territorio de Ciudad Juárez se difunde en distintos asentamientos entre los que se citan colonias y fraccionamientos que responden a procesos fundacionales, crecimiento y desarrollo en forma heterogénea, con lo cual las visiones, usos y prácticas detonan acciones y formas de pensamientos diferentes que los hacen especiales en su entorno de manera significativa.

El objetivo central de este estudio es identificar las formas en las que los residentes urbanos de la ciudad construyen social y culturalmente sus maneras de ver y representar el lugar donde habitan y conviven cotidianamente, además de señalar las visiones e imaginarios que se desprenden en relación con la forma específica de habitar el entorno donde decidieron asentarse, tomando en cuenta las experiencias, trayectorias y vivencias que son rescatadas de sus pensamientos y así ocupar su colonia o fraccionamiento.

Ante ello, la propuesta metodológica de este estudio parte de entender la postura y acción de los residentes vistas desde sus propias experiencias urbanas, apoyándonos, para ello, en el

1 Docente investigador de la Universidad Autónoma de Ciudad Juárez, México. Correo electrónico: ramon.moreno@uacj.mx 
paradigma de la fenomenología cualitativa, lo cual nos conduce a entender la relación entre el relato, la acción y la experiencia de vivir e imaginar Ciudad Juárez. Asimismo, se apoya en los recorridos de campo en forma directa a los lugares de residencia de los actores mediante la realización de entrevistas, observación directa, cartografía y uso de la fotografía.

Palabras clave: procesos espaciales, relatos urbanos, imaginarios, frontera.

\section{ABSTRACT}

At present the territory of Ciudad Juárez extends in different settlements which are mentioned as colonies and fractionations that respond to foundational processes, growth, and development in heterogenous form, whereby visions, uses, and practices detonate different actions and thoughts forms that make them special in their environment significantly.

The central objective of this study is to identify the ways in which urban residents of the city socially and culturally construct their ways of seeing and representing the place where they live and coexist daily, besides of pointing out the visions and imaginaries that emerge in relation to the specific way of inhabiting the environment where they decided to settle, taking the experiences and trajectories that are rescued from their thoughts and so occupying their colony or fractionation.

In view of this, the methodological proposal of this study starts from understanding the attitude and action of the residents seen from their own urban experiences, supporting us in the paradigm of the qualitative phenomenology which leads us to understand the relation between the story, the action, and the experience of living and imagining Ciudad Juárez. Likewise, it relies on the field trips directly to the places of residence of the actors through interviews, direct observation, cartography, and use of photography.

Keywords: spatial processes, urban narratives, imaginaries, frontier. 
Procesos espaciales, habitaR E IMAGinARIOS EN LOS ESPACIOS URBANOS...

\section{INTRODUCCIÓN}

El lugar es una forma de visualizar realidades, definir experiencias y percibir imágenes; donde el habitar se inserta para construir acciones y especificar cotidianidades para vincularlas con el territorio en el cual se desarrollan diversas tareas como vivir, pensar, pasear, recorrer el mismo, por medio de los elementos que se presentan cotidianamente en él y donde los seres humanos pueden reflexionar acerca de la importancia de convivir con el medioambiente que se genera, ya sea natural o social; donde las interacciones con los demás se vuelven importantes para su desarrollo y crecimiento.

Por otro lado, el mismo concepto se relaciona con el espacio como mecanismo de relación con el ser humano, para comprender las situaciones cotidianas que se generan constantemente en esos lugares donde se asientan, que pueden ser barrios, colonias o fraccionamientos, y en los cuales los procesos de adaptación y socialización adquieren matices específicas en cuanto a su entorno inmediato y el próximo, es decir, su familia, en el primer caso, y los vecinos, en el segundo; ahí donde las esferas de convivencia muestran patrones especiales en cada rincón urbano.

El objetivo de este estudio es conocer los mecanismos que utilizan los habitantes de la ciudad para vincularse directamente con el lugar donde se asientan, además de explicar los significados que se derivan de esas formas de socialización y, sobre todo, la vinculación que tienen con el territorio, el habitar y los imaginarios.

A través de las experiencias individuales o colectivas en el medio urbano, se permite conocer las trayectorias que establecen los seres humanos al vivir, ocupar y convivir con él; donde se gestan nuevas modalidades de interacciones que se ejemplifican por medio de costumbres, usos o tradiciones que dan vida y permiten crear relaciones con la colonia o fraccionamiento, considerados como parte fundamental del lugar donde se establecen. Es importante hacer la aclaración respectiva de que interesa destacar el sentido del lugar como elemento que configura las relaciones con el espacio como connotación de las formas de vida que se 
generan. En este sentido, Ramírez y López (2015) señalan que “el lugar remite a la habitabilidad, a la apropiación y a la articulación del espacio" (p. 161), por lo que es esta orientación a la que se dirige este estudio, sobre todo particularizando los elementos sobresalientes de los residentes de una colonia o fraccionamiento en el ámbito urbano, y visualizando las categorías de la apropiación del espacio y su conexión con el habitar y los imaginarios. Tal y como lo expresa Méndez (2015), "los barrios y pueblos son todo lugar. Desplegarlos, describirlos y descifrarlos implica rescatar las historias que de ellos se platican o narran” (p. 17).

En este sentido, el arte de relatar experiencias y vivencias forma parte del ingrediente de estos actos; se vive, piensa y determina la ciudad como un espacio de encuentro y desencuentro de objetividad y subjetividad; la calle es un elemento esencial de pertenencia, práctica o simplemente habitar el espacio. Así, entonces, la ciudad es una parte de ese mosaico de interacciones que interesa dibujar en el momento en el que los residentes experimentan el habitar en una colonia o fraccionamiento determinado.

Ahí donde se mezclan el espacio y el territorio como elementos fundamentales en la integración de acciones específicas que se gestan en cada asentamiento humano de la ciudad, en las cuales la imagen, los pensamientos y las acciones se vuelven parte fundamental de la vida de quien habita la ciudad y en donde se entrelazan historias, trayectorias o experiencias que asumen los residentes al recorrer, transitar o experimentar la vida urbana.

En estos contextos surgen algunas ideas de cómo analizar el espacio urbano en relación con el habitar y los imaginarios; las maneras en cómo los residentes crean estas representaciones en su quehacer diario de vivir en Ciudad Juárez. A partir de ello, la estrategia metodológica para abordar el estudio parte de un enfoque socioespacial en el que se vislumbra el análisis del lugar donde se vive como referente principal para entender los hechos que están directamente relacionados con el residente o grupos de habitantes que se han seleccionado para la interpretación de sus experiencias de habitar esta ciudad fronteriza del norte de Chihuahua, apoyándonos en testimonios y relatos de los entre- 
vistados seleccionados para este estudio, así como en material fotográfico (obtenido en recorrido de campo) y cartografía con la triangulación de las técnicas anteriormente citadas.

El trabajo estará organizado en tres niveles de análisis: primero, el enfoque teórico, que es seleccionado para reforzar la información empírica del estudio; segundo, el marco contextual del lugar de residencia de los entrevistados; y, finalmente, sus relatos y testimonios.

\section{PRIMER NIVEL DE ANÁLISIS: ENFOQUE TEÓRICO DEL LUGAR, EL HABI- TAR Y LOS IMAGINARIOS}

Es la sección que aborda las diversas conceptualizaciones de cómo se vinculan los tres elementos clave de este trabajo.

Se parte de la idea de la ciudad como un espacio geográfico donde ocurren distintos hechos que hacen que el residente la vea como un factor de crecimiento y desarrollo, donde variables como la arquitectura, economía, historia, urbanismo, cultura y sociedad cumplen con el rol de comprender las dimensiones de los procesos espaciales que en ella ocurren y que permiten observar la configuración de distintos asentamientos a lo largo y ancho de la ciudad. En esta orientación se retoman algunos conceptos principales para entender la dinámica que interesa resaltar. Particularmente se explica en este estudio la vinculación de los conceptos clave que dan pie al mismo: lugar, habitar e imaginarios como elementos que expresan una forma de vida e incorporación al espacio que se genera en el entorno urbano; donde los ambientes sociales, geográficos, urbanos, económicos y culturales parecieran desatar un sistema de redes complejas que se suscitan continuamente en el interior de sus asentamientos humanos.

Así, entonces, el lugar, como lo refieren Ramírez y López (2015), son

los principales elementos que le dan significado al lugar y que son del espíritu y la personalidad que se hacen patentes cuando la población se expresa sentimentalmente con respecto a un sitio. El es- 
píritu tiene que ver con su esencia y la personalidad con aquello que los hace únicos y diferentes. Desde este enfoque, la personalidad se configura a partir de las características naturales del lugar y de la forma en que el ser humano las ha moldeado" (p. 165),

reflexión que nos permite profundizar en la relación que establece el ser humano con un lugar específico que puede ser su barrio, colonia o fraccionamiento, y sobre todo, con el aspecto que tiene que ver con el sentido de vivir la ciudad y su relación con las experiencias en el lugar donde habita.

A partir de lo anterior, la siguiente idea establece un vínculo importante del lugar y el habitar:

un Lugar es un fragmento de naturaleza iluminada por el obrar del ser humano o una construcción entreverada de naturaleza, y la verdadera casa que aspire a convertirse en un lugar tiene que convertirse de su condición de residencia para devenir a habitación, esto es, el espacio en el que se habita (Prieto, 2011, p. 75).

En esta reflexión se puede encontrar la importancia de entender el lugar como parte fundamental en la creación de interacciones que identifiquen el actuar de los habitantes de la ciudad en donde las condiciones sociales, culturales y urbanas manifiestan procesos de comportamiento específicos, así como construcción de significados de relevancia en sus relaciones individuales, grupales y espaciales.

Orientación que permite, a su vez, explicar y en un segundo momento identificar las cualidades que surgen, tanto en el medio físico como en aquel donde el habitante interviene, es decir, en lo social y cultural. En este sentido, Camacho (2002) sostiene que "el hombre crea su realidad y su contexto social incluidos tanto los objetos como el espacio y tiempo, en los cuales vive y se desarrolla, construyendo de esta forma su hábitat: casa, edificio, área urbana o contexto regional" (p. 81), cita que nos lleva, entonces, a describir las realidades que se dan en una ciudad específica, 
donde tanto el medio físico natural como el construido son reflejo de lo que sus habitantes piensan y hacen.

Así, en esos términos,

el espacio es otorgado por los lugares: es un don que surge de una especie de generosidad creativa. Los lugares marcan, además de una referencia, 'irradian' significados que se despliegan en relaciones en entre las cosas que pueden ser medidas (Prieto, 2011, p. 80).

Buenos momentos para expresar cómo, entonces, los habitantes citadinos se ven sumergidos en sus propias experiencias en el momento, el lugar y las relaciones que establecen entre ellos y los espacios donde se asientan, dinámicas que sirven para entender las expresiones que ellos mismos señalan, por ejemplo, las calles, su casa, la plaza, su entorno, los vecinos y otros actores que se involucran en sus acciones cotidianas; por tanto, la función que juegan estos elementos es parte fundamental de sus propias experiencias y, además, de los mecanismos adquiridos en sus vivencias cotidianas.

Esos momentos es lo que interesa destacar en este estudio donde los residentes explican y describen sus experiencias y, de ellas, se construyen significados de los espacios donde habitan. En relación con lo anterior, el lugar dentro del espacio urbano es una variable no solo a nivel de medición cuantitativa, sino también cualitativa, puesto que son las expresiones que dan un simbolismo a ese sitio o zona donde el residente se asienta. En ese sentido, el imaginario del habitar se hace presente por medio de los usos, prácticas, lenguaje y otras maneras que asume en ese sitio, el cual se convierte en un aspecto fundamental para el conocimiento de los significados y representaciones que se generan en el mismo. Con respecto de lo descrito anteriormente, el

imaginario es un conjunto de imágenes social, temporal y espacialmente compartido. Hay imaginarios generales de carácter ético, jurídico y económico que atraviesan y cohesionan dicho conjunto. Estos se acompañan del imaginario del orden engendrado y configurado 
desde tiempos remotos a partir de valoraciones primarias, como luzoscuridad, frío-calor, fuego-agua, tierra-aire o seguridad-inseguridad, dualidades cuyo germen es ya la diferenciación ordenadora (Méndez, 2015, p. 27).

En este discurso se ubican las siguientes aportaciones: primero, la idea del imaginario, que es el seguimiento de reglas, representaciones y formaciones discursivas y sociales profundas, de honda manifestación cultural (Silva, 2013), sentido que concuerda con la idea de Méndez (2015), expresada en párrafos anteriores, y con lo que Moreno (2015) agrega como procesos socioespaciales, es decir, aquellas actividades que se generan en el territorio, las cuales implican elementos de relación con el mismo y en donde se observa una conjunción de indicadores cualitativos que ayudan definitivamente a comprender las experiencias que ocurren en un sitio específico.

Por otro lado, Fuentes y Rosado (2015) expresan que "los imaginarios son construidos por las prácticas y vivencias concretas de los ciudadanos, los discursos de diversos medios y las imaginación de sus creadores" (p. 84), o bien, como señala Méndez (2015):

la ciudad como producto y proceso de construcción social del territorio apoyada en relaciones materiales y culturales, integrada por un conglomerado humano diverso, cohesionada por instituciones y anclada en el espacio físico se nutre constantemente de su capacidad de sustento y participación en la red global, así como de relatos e imágenes de lo que fue, lo que es y lo que podría ser (p. 27).

En relación con la conexión entre lugar, habitar e imaginarios, las siguientes aportaciones ayudan a establecer estos lazos en la conjugación de las acciones humanas que realizan los residentes de alguna colonia o fraccionamiento dentro de la dinámica urbana. Moreno (2015), se refiere al

habitar como un proceso que desarrollan los individuos en el espacio donde viven: casa, ciudad, trabajo, donde realizan interacciones 
Procesos espaciales, habitar E imaginaRios EN LOS ESPACiOS URBANOS...

cotidianas en las que distintas posiciones y prácticas (habitus) se entretejen para canalizar los mecanismos propios de cada sujeto en el asentamiento urbano que habita y el grupo humano que lo rodea (p. 258).

En otro orden de ideas, Silva (2013) establece el concepto de "urbanismo ciudadano", donde explica que este

se vive en las ciudades, según los imaginarios que los habitantes construyen y comparten de ella, donde las percepciones grupales hacen los nuevos croquis ciudadanos y desde donde se puede pensar en conquistas sociales basadas en deseos subversores de los habitantes del cosmos de cada ciudad (p. 64);

así, entonces, el espacio vivido por los habitantes urbanos es un factor que genera distintas explicaciones y significados en su cotidianidad, tal y como lo exponen, en primer término, Méndez (2015), en el sentido de que "la narrativa tiene lugar, se remite a eventos temporales y espaciales, así sean lugares y relatos ficticios: siempre está referida a una trama de ideas, valores, sentimientos y acontecimientos en algún sitio" (p. 29), y en segundo lugar, Moreno (2015), quien establece que

el análisis del habitar permite entender las formas de vinculación que adopta el ser humano con respecto a su entorno, procesos de evaluación con el tiempo y el espacio marcan los procesos particulares que se entretejen en el mismo, dando una relevancia significativa a como se han estructurado las diversas acciones que los individuos realizan en el lugar que eligen para vivir (p. 259).

A partir de estos elementos retomamos la siguiente expresión de Ramírez y López (2015) en el sentido de que "desde la perspectiva humanista, el lugar es un ámbito donde la subjetividad toma relevancia, por ende, el sentido adquiere significado a partir del individuo, de sus emociones y sus percepciones" (p. 166), que se complementa con lo expresado por Méndez (2015): 
el lugar se significa y re significa desde su posición cambiante como parte de un entramado, como constituido por elementos diversos y como sistema de relaciones. Ahora, el lugar es un escenario dispuesto para emitir mensajes, para persuadir al sujeto y para propiciar acciones y comportamientos determinados, de ahí que requiera de la coherencia interna en la medida en que su forma, significado y lenguajes se correspondan con las prácticas que en él se realizan (p. 21).

Así, entonces, interesa resaltar los procesos, usos y prácticas que tienen los residentes de las ciudades, en este caso de Ciudad Juárez: la idea del lugar-habitar e imaginarios como parte de la sociología y geografía urbana que identifica a esta localidad fronteriza. De esta manera, "la organización del espacio urbano es reflejo de la sociedad en contextos culturales, políticos, sociales y ecológicos específicos y paralelamente, de los recursos disponibles, los deseos y los imaginarios de quienes buscan habitar las ciudades" (Félix, 2016, p. 48).

\section{SEGUNDO NIVEL DE ANÁLISIS: CIUDAD JUÁREZ: LUGARES, HABITAR E IMAGINARIOS}

Los procesos de habitar e imaginarios que se integran en el concepto de lugar, permiten el abordaje en un asentamiento urbano específico que vislumbre cualidades concretas en una ciudad en específico, como es el caso de Ciudad Juárez. De acuerdo con las posturas de Moreno (2015), Méndez (2015), Silva (2013), Fuentes y Rosado (2015), entre otros, se conectan estos elementos para comprender el funcionamiento y la estructura del espacio urbano como parte de las acciones y prácticas que realizan los residentes al llegar a ocupar su vivienda, la calle o el parque donde se asientan en forma temporal o definitiva.

Al respecto nos interesa ver cómo se construyen los significados, usos y prácticas de los residentes de una ciudad en la cual se integran estos elementos. Para ello y de acuerdo con Félix (2016), "La ciudad se presenta como un mosaico de entornos desiguales y contrastantes, no solo en sus características físicas y su conec- 
tividad con la ciudad como un todo, sino en la población que los habita" (p. 52); o como lo cita Licona (2007),

la ciudad es un espacio económico por excelencia, pero las acciones sociales que se manifiestan en la misma no se pueden explicar partiendo únicamente del enfoque económico, porque la ciudad es también lugar de un sinfín de relaciones sociales, políticas, religiosas étnicas, simbólicas, culturales, etc., que determinan el uso y apropiación del espacio urbano. Son los habitantes los que a partir de su posición de grupo o clase y su localización en la ciudad, se apropian del espacio urbano y lo significan. Construyen sentidos y modos de habitar (p. 14).

Bajo estas premisas interesa resaltar en esta sección el estudio de la relación del espacio urbano —el vivido- y los relatos de los actores que viven o habitan en Ciudad Juárez, localidad fronteriza del norte del estado de Chihuahua, cuyos contrastes físicos, sociales e históricos se delimitan a partir del río Bravo, creando así una ciudad cuyo crecimiento urbano se manifiesta en diversos matices, no solo a nivel territorial, social, económico, urbanístico y espacial, donde las narrativas, el lugar, los imaginarios, se insertan a través del tiempo y del espacio. Particularmente estos enlaces son los que interesa describir y explicar a partir de retratos de los paisajes urbanos, sociales y culturales que se han edificado en su estructura territorial, coincidiendo con los elementos que aportan tanto Licona (2007) como Félix (2016) en el sentido de la formación y construcción del lugar como elemento simbólico y sociológico que opera en las distintas colonias y fraccionamientos de Ciudad Juárez. A propósito de conocer y recorrer la ciudad durante distintos momentos, lo cual permite dibujar diversos entornos y lugares para su análisis e interpretación a nivel social, cultural y urbano.

El habitar en Ciudad Juárez adquiere diversas connotaciones en cuanto al espacio físico donde se han construido distintas colonias y fraccionamientos, los cuales representan en su gran mayoría una diversidad en cuanto a características demográficas que se sustentan en condiciones en donde los individuos han manifes- 
tado su deseo de radicar, o bien, de acuerdo con las posibilidades que han tenido al llegar a vivir en la ciudad -las condiciones de construir un hogar en algún rincón de la misma-, nos invita a visualizar las mismas cualidades que se han asumido durante el tiempo que han permanecido en ella.

Los diversos procesos a nivel geográfico y de construcción del territorio son indicadores que sirven de referencia para identificar los elementos específicos del habitar y de formación de imaginarios en los lugares de Ciudad Juárez. Esta cartografía representa, a su vez, los diferentes grupos que se han establecido y que también son vínculos importantes en el análisis geográfico del lugar urbano, como el barrio, la colonia o el fraccionamiento; donde se desarrollan acciones, convivencias, ocupación del espacio, diseño de diversas tipologías de vivienda, usos en las calles, parques o plazas, que a su vez orienten a dibujar concretamente cómo los citadinos de Ciudad Juárez viven o definen su propia ciudad, tal como lo señala Méndez (2015): "Los lugares elegidos para reconstruir historias en cada ciudad son los de mayor centralidad, los cuales, por definición, serían los de mayor intensidad lumínica” (p. 20). Este señalamiento va en ese sentido y relacionado directamente con el constructo del habitar y los imaginarios en cada rincón, territorio o asentamiento que se ha formado en esta ciudad fronteriza.

El mapa 1 es una relación entre el habitar, el espacio urbano y los imaginarios, el cual fue realizado por medio de recorridos de campo, investigación documental, en particular de los procesos históricos, sociales y espaciales que han ocurrido en la ciudad durante los distintos tiempos, y entrevistas que se han registrado en las visitas a los distintos sitios, dando por resultado las cinco zonas que aparecen en el mismo, las cuales describen los procesos de formación, crecimiento y desarrollo que se han tenido en la ciudad relacionados con el habitar, la construcción del lugar y la inclusión de los imaginarios, que son producto de esa diversificación en el suelo y territorio de Ciudad Juárez.

El habitar y el lugar que se han construido en esta ciudad fronteriza y que se ubican en el mapa 1, responden a las acciones 
y formas de ocupación de sus residentes a través del tiempo, los cuales se resumen en los siguientes procesos:

Primero: procesos fundacionales (áreas 1 y 2), desde 1884 hasta 1930, donde se incluyen el centro, poniente y parte del sur, cuyos espacios físicos marcan diversas condiciones en la vida cotidiana de Ciudad Juárez. Prácticamente los procesos de construcción del espacio urbano tienen como características las siguientes:

a) Crecimiento concéntrico con trazas reticular y ortogonal en algunos sectores.

b) Expansión al poniente, sin considerar el medio físico natural, sobre todo con los arroyos y ríos del lugar.

c) Presencia de diversos grupos sociales, económicos y urbanos en partes de la zona norponiente, generando, con ello, diversos constructos del lugar en diversos momentos de su desarrollo social.

Segundo: los relatos y experiencias de vivir la ciudad se sitúan en la categoría de evolución y expansión de la misma hacia la parte sur y oriente del territorio de esta localidad fronteriza (zonas 3 y 4); la convergencia en territorios dispersos y poco compactos de la población de los sectores medios, bajos y, en algunos casos, altos, retrata formas de vida distintas, pero eso no hace pensar en la estructuración diferencial de la población en las áreas 3 y 4, con lo cual se empiezan a edificar nuevas experiencias, además de los tipos de asentamientos económicos que se van a mezclar en esta parte del territorio de la ciudad.

a) Se crean asentamientos irregulares en el surponiente y, además, la invasión a las zonas agrícolas del oriente, produciendo nuevas maneras de construcción de vivienda y, por tanto, de creación de hábitats distintos.

b) Es un periodo que comprende desde 1930 hasta 1960 con la modificación de los lugares urbanos para vivir, trabajar y crecer social, educativa y culturalmente, y en donde aparecen los programas federales de impulso al crecimiento 
e imagen urbana de manera sustancial, como el Nacional Fronterizo (Pronaf) y el de Industrialización Fronteriza (PIF). La traza urbana se va deformando y adquiere nuevas modalidades en las zonas 3 y 4 . Tal y como lo señala Peña (2015):

el nivel de dependencia de las actividades económicas de la ciudad con la industria maquiladora, en la crisis del 2008, fue el detonante para reflexionar en el tipo de ciudad que todos anhelamos, donde todos prosperamos y contamos con beneficios del desarrollo urbano tan promulgado a través de la venta masiva de casas (p. 255).

Tercero: la zona 5, invasión y ocupación de sectores medios y altos en territorios que se consideraban zonas de reserva, integra esta parte de la ciudad ubicada entre el norte y el oriente, que constituye nuevas representaciones del habitar. En esta fase de expansión, la ciudad permite la construcción de nuevos asentamientos populares, medios y de clase alta para distinguir un grupo de otros. En esta etapa, desde 1960 hasta 2017, las cualidades que se identifican son el crecimiento y la expansión de vivienda de interés social hacia el suroriente, así como la presencia de grupos económicos con medianos y altos ingresos hacia la parte oriente, para concentrarse en las figuras de los condominios y fraccionamientos cerrados. Estas etapas marcan singulares estilos de vida de los residentes citadinos, ya que tienden a diferenciarse unos de otros de acuerdo con el estilo de vida que asumen en este tipo de asentamientos humanos.

Dos elementos reflexivos en la construcción de la relación lugar-habitar-imaginarios, se desprenden de las siguientes aportaciones: en primer término, Limas (2010) establece que

otros impactos provocados por la localización de la industria maquiladora en Juárez, incluyen la incorporación de las mujeres en el mercado laboral asalariado y la constitución de la ciudad como un polo de atracción para migrantes. Esta dinámica representó incre- 
mentos en los ingresos de los hogares y una reconformación de las estructuras familiares (p. 64).

Un segundo momento de reflexión lo establece Moreno (2015), quien señala que

las transformaciones que se han presentado en la antigua Paso del Norte [etapas 1 y 2 del mapa 1], han creado una ciudad con diferentes sectores de población que se han asentado en en colonias o fraccionamientos con características sociales, económicas, demográficas y culturales, además han contribuido a retratar imagenes propias en cada uno de ellos, y a su vez han originado al interior de la ciudad una economía diversificada que la hacen verse como un centro de atracción para la población que busca mejorar sus condiciones de vida (p. 265). 
Mapa 1. Zonas relacionadas con el habitar y los imaginarios

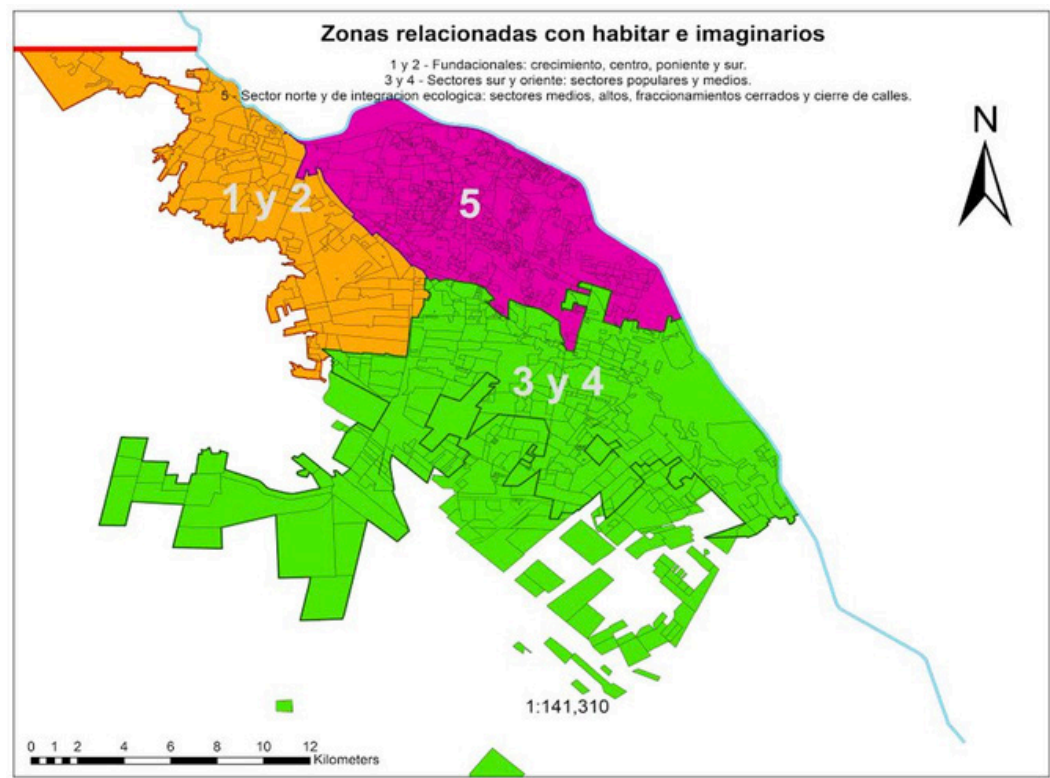

Fuente: Moreno (2015); archivos de recorridos de campo e investigación documental.

\section{ESCENARIOS Y LUGARES EN LA CONSTRUCCIÓN DEL HABITAR Y LOS IMAGINARIOS EN CIUDAD JUÁREZ}

En secuencia a las reflexiones anteriores y bajo la lupa de la fotografía, y en relación con el mapa 1, se han elegido como muestras algunos de los asentamientos que se han dibujado en el contexto urbano, los cuales vinculan estos procesos de los residentes de adquirir el lugar donde se asientan, conviven y desarrollan sus propios momentos, tal y como lo han señalado los autores consultados en el eje de análisis teórico de este trabajo. Las emociones, percepciones e imágenes, se revelan en cuanto a las formas propias del habitar y del entorno que se ha reflejado a través del tiempo y el espacio en la vida urbana de Ciudad Juárez.

La figura 1 incluye los distintos lugares de la ciudad que se han construido en diversos momentos y contextos que, aparente- 
mente y de acuerdo con las imágenes, muestran contrastes entre la estructura física y social donde se han establecido los residentes de la ciudad. Las imágenes de la figura 1 contienen algunos elementos importantes de las zonas sur, poniente y surponiente, donde las trazas urbanas configuran diferentes asentamientos humanos, cuyas condiciones económicas, sociales, culturales e históricas edifican nuevos procesos socioespaciales en la vida cotidiana de esta ciudad fronteriza.

Figura 1. El territorio urbano en Ciudad Juárez

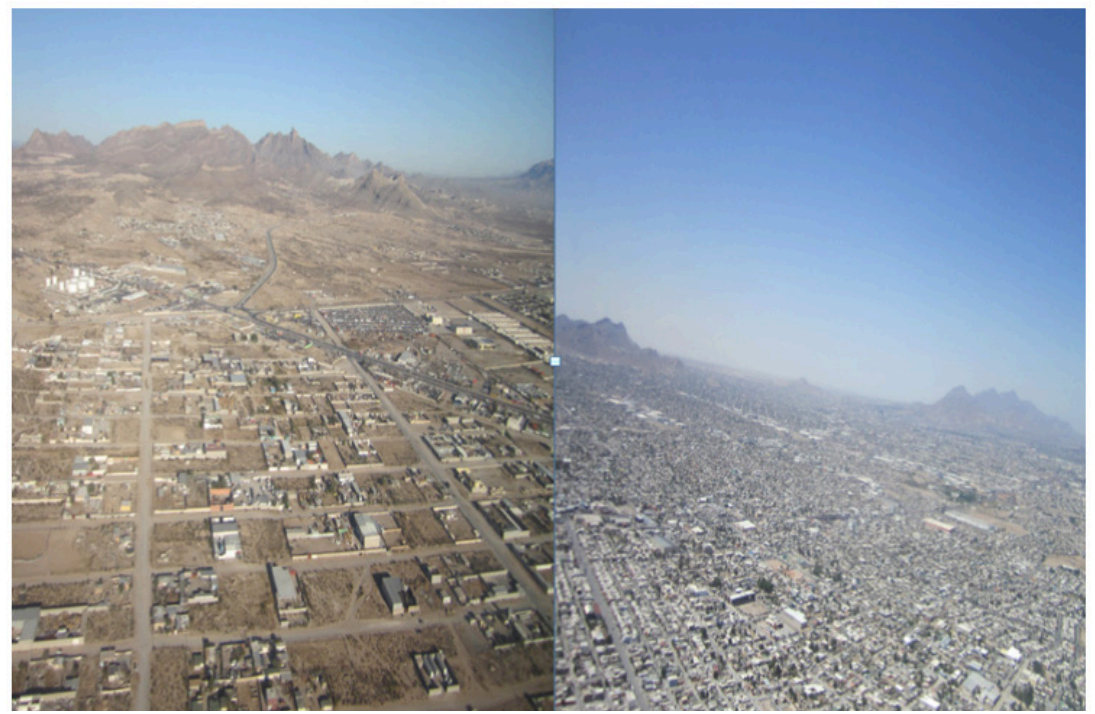

Fuente: Moreno (2016); archivo personal.

El territorio de Ciudad Juárez forma divergencias en sus distintos asentamientos humanos, historias, experiencias y maneras de construir su cotidianidad, lo cual nos lleva a pensar en los procesos que realizan sus habitantes, ya sea en su vivienda, calles que recorren, tiendas donde se encuentran con sus vecinos para conversar, entre otras actividades que llevan a cabo en el espacio donde les tocó vivir.

Así, en la figura 2 se observan dos partes de la ciudad: el oriente y el suroriente, ambas con distintas trazas y, por tanto, con diversas 
viviendas, culturas, socialización, economías y trayectorias. En esta composición de fotografías, la ciudad adquiere matices con condiciones territoriales que parecieran marcar nuevas maneras de ocupar el espacio; espejos que traslucen la relación que existe entre el hombre y la naturaleza; mecanismos que se integran a las maneras de habitar el espacio urbano y donde los contrastes morfológicos iluminan los lugares específicos de esta ciudad fronteriza del norte del estado de Chihuahua con ese resplandor en sus cotidianidades y donde las construcciones de la obra del ser humano marcan o señalan los espacios para la vida del residente; así, el oriente y el suroriente, que se integran en la figura 2, son parte del lugar que se genera en esta zona de la ciudad.

\section{Figura 2. Espacio urbano en el oriente y suroriente de Ciudad Juárez}

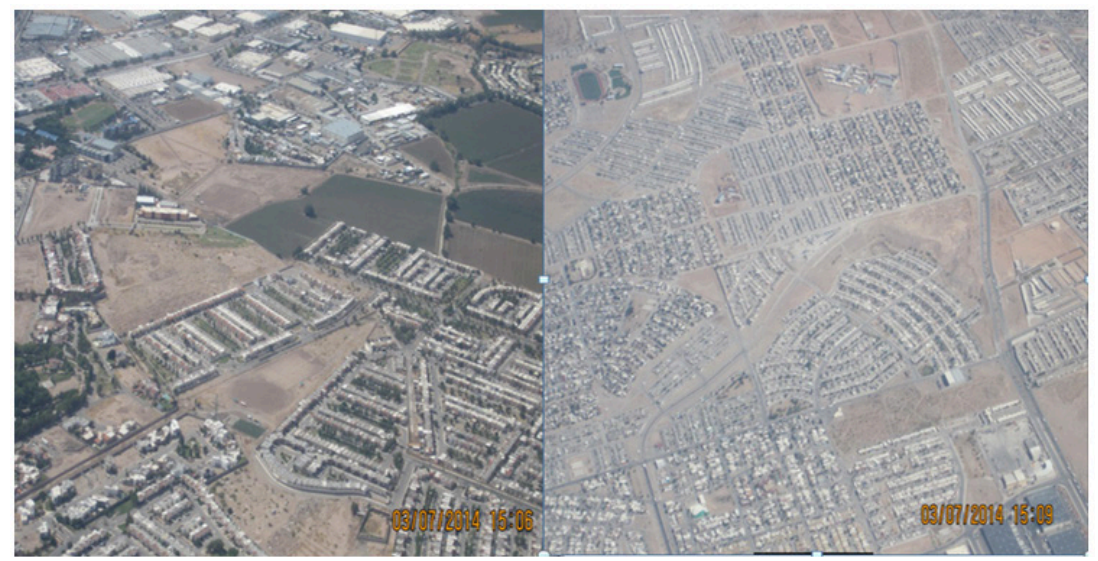

Fuente: Moreno (2016); archivo fotográfico.

Respecto de lo que señalan Peña (2015) y Moreno (2015), los escenarios de vivir Ciudad Juárez se ejemplifican en distintos espacios que se han construido en la figura 3, sectores de vivienda que se establecen en las zonas que se construyeron para este estudio en el mapa 1, el cual retoma diversas imágenes para ilustrar cómo, cuándo y de qué manera sus residentes han hecho de su colonia o fraccionamiento un lugar para habitar y edificar sus propios emblemas y significados. 
La figura 3 señala cuatro tipos de escenarios: el primero, señalado con la letra A, corresponde a una colonia visitada en el poniente (zonas 1 y 2), en la cual se pueden ubicar algunos elementos urbanos importantes: terrenos ubicados en la parte de un cerro con viviendas establecidas bajo modelos de autoconstrucción, con problemas de equipamiento y calles que están pavimentadas o no, áreas que, a su vez, se reflejan en las experiencias propias de sus habitantes, donde las historias urbanas y la creación de mundos ideales del habitar, se moldean por cuenta propia de sus residentes.

El segundo escenario (foto B) corresponde a un prototipo de vivienda diseñada para trabajadores de diversos sectores económicos, a través de los programas federales de impulso a la misma vía el Instituto del Fondo Nacional de la Vivienda para los Trabajadores (Infonavit), y en donde se definieron modelos traídos del centro de la República Mexicana para ser implementados en distintas partes de la ciudad. El caso de esta fotografía corresponde al denominado conjunto habitacional Casas Grandes situado en la zona 3 del mapa 1, donde grupos heterogéneos de población llegaron, ocuparon y diseñaron sus propios lugares de vida o, como lo menciona Silva (2013),

un imaginario ciudadano, el cual es producido por los residentes que viven en las ciudades según las percepciones que los habitantes construyen de ella, donde las miradas grupales producen los nuevos croquis ciudadanos y desde donde se puede pensar en conquistas sociales basadas en deseos subversores de los habitantes (p. 162).

Los escenarios que se muestran en las fotos $\mathrm{C}$ y $\mathrm{D}$ son de tipos de viviendas edificadas en Ciudad Juárez (zonas 4 y 5 del mapa 1, respectivamente), cuyos símbolos —su ubicación- son precisamente lo que orienta a crear espacios vividos diferentes. En el caso de la fotografía $\mathrm{C}$ (suroriente, vivienda de interés social) y en el de la D (nororiente, urbanizaciones cerradas), el habitar se edifica de manera distinta con significados representativos del lugar donde los grupos residentes adquieren diferentes experiencias, trayectorias y pensamientos urbanos. Es entonces que, a partir de 
los imaginarios, "se busca aprehender y comprender las características y atributos reales o irreales de la ciudad y la vida urbana. Son un un tipo de gnoseología urbana del ser y el estar, del habitar y el trabajar" (Fuentes, \& Rosado, 2015, p. 84). Es a partir de los elementos simbólicos que se reflejan en la construcción de las imágenes de la figura 3 que se establece una relación de fortaleza entre el lugar, el habitar y los imaginarios.

Figura 3. El habitar en distintos escenarios de Ciudad Juárez

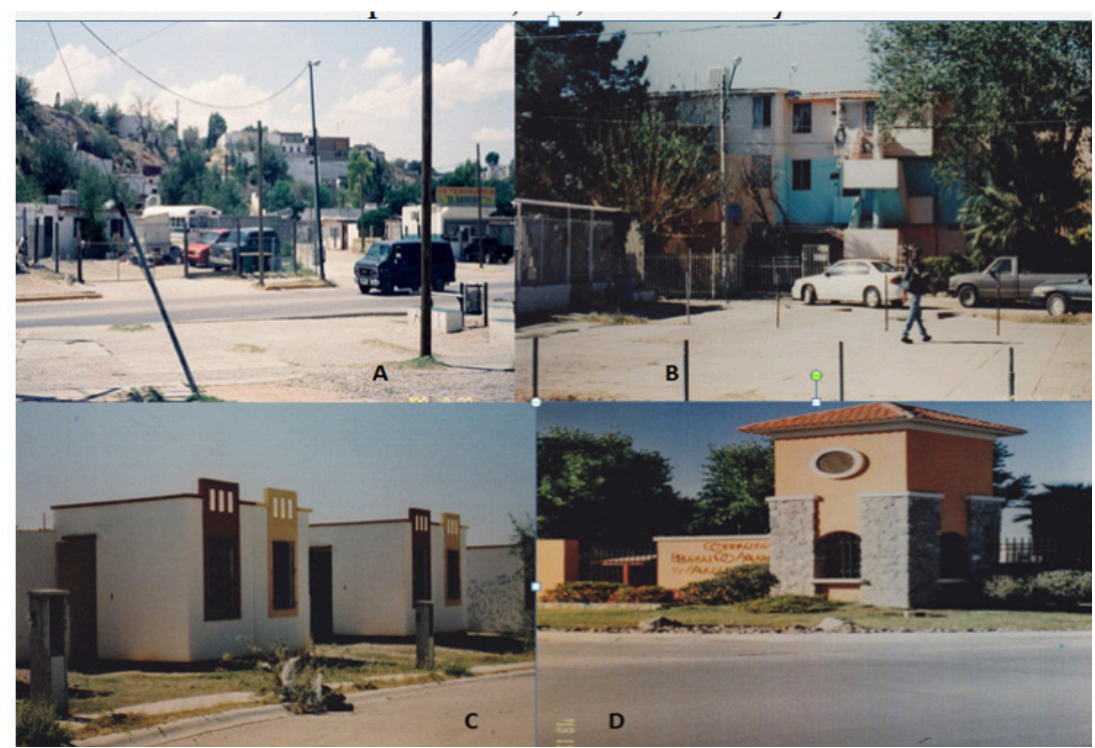

Fuente: Moreno (2016); archivos de recorrido de campo.

\section{TERCER NIVEL DE ANÁLISIS: TESTIMONIOS Y RELATOS DE VIVIR CIUDAD JUÁREZ}

A partir de los conceptos de lugar, habitar e imaginarios recurrimos a experiencias de los residentes seleccionados para este ejercicio de entender y comprender cómo se vive la ciudad. Para ello, nos hemos apoyado en la metodología interpretativa del enfoque cualitativo en donde nos interesa rescatar los testimonios de los habitantes seleccionados, a través de un muestreo no pro- 
babilístico para identificar un grupo de personas que residieran en, al menos, alguno de los espacios que se añaden en el mapa 1, aplicando un cuestionario con elementos no solo de cohorte cuantitativo, sino también algunos reactivos de tipo cualitativo, que nos permitieran vislumbrar de manera adecuada la definición y creación de significados específicos dentro del espacio urbano donde viven cotidianamente.

Los resultados obtenidos por medio de esta metodología mixta nos permiten identificar situaciones y hechos concretos a través de las experiencias de sus residentes, en donde se empleó un total de ciento diez instrumentos aplicados en veinte colonias que se muestran en el mapa 2. Las siete primeras colonias: 1) El Fortín, 2) Villa Colonial, 3) Infonavit Juárez Nuevo, 4) Riberas del Bravo, 5) Benito Juárez, 6) Quinta Esmeralda y 7) Granjas de Chapultepec, resultaron con el mayor número de instrumentos aplicados, mientras que 8) Arroyo Colorado, 9) Infonavit Ampliación Aeropuerto, 10) Turquesa y 11) Niños Héroes, tuvieron el segundo lugar en la aplicación del cuestionario de apoyo; y en tercer momento las colonias señaladas con los números 12 al 20 corresponden a números menores en la generación de relatos de sus residentes; sin embargo, a pesar de ello, las narrativas obtenidas de cada uno de ellos son parte fundamental en la construcción de experiencias que se viven a lo largo y ancho del territorio de Ciudad Juárez. 
Mapa 2. El habitar y el lugar de residencia de los entrevistados

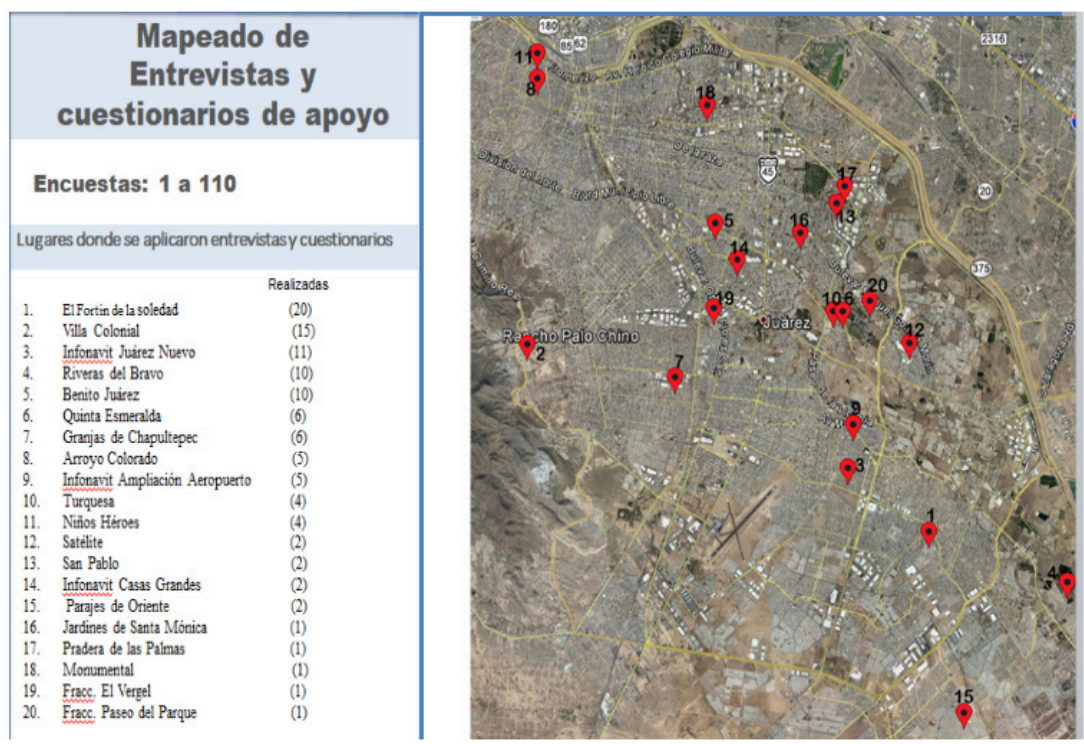

Fuente: Moreno (2017); archivos de recorrido de campo.

Con el objetivo de dar el peso necesario a los testimonios de los entrevistados y ante la limitada extensión en este trabajo, se tomó la decisión de incorporar los ciento diez instrumentos aplicados tomando una muestra de casos representativos que nos indicara los escenarios que se crean en torno al habitar, el lugar y los imaginarios en Ciudad Juárez, considerando las condiciones en las que los entrevistados definieron su propio medioambiente.

\section{CUALIDADES DEMOGRÁFICAS DE LOS ACTORES SELECCIONADOS}

En relación con el grupo de edad, los residentes resultaron tener entre veinte y cuarenta y nueve años de edad, lo que significa una población adulta. Con respecto a su tiempo de residencia en la ciudad, quienes obtuvieron un mayor puntaje son aquellos que tienen entre once y quince años viviendo en Ciudad Juárez, seguidos de quienes tienen de cero a cinco años, y en tercer término quienes tienen de seis a diez años, lo que nos habla de la 
diversidad de experiencias que se obtienen en la colonia o fraccionamiento donde viven. De igual manera, hay un grupo significativo de esta variable demográfica que también tiene relevancia en este estudio: aquellos que señalaron tener de dieciséis a veinte años de residencia, seguidos muy de cerca de quienes tienen entre veintiuno y treinta años de vivir en Ciudad Juárez.

Los imaginarios de estos grupos que señalan esa temporalidad señalan una amplitud en el manejo de la información de sus lugares y, por tanto, un grado mayor de cohesión en cuanto a las trayectorias que han realizado en todo el territorio urbano. En el estado civil, la población casada forma parte de este importante conjunto de residentes que nos relataron, de manera franca y abierta, sus testimonios, tal y como lo han señalado en sus aportes Silva (2013), Moreno (2015), Fuentes y Rosado (2015) y Félix (2016).

\section{RELATOS Y ESCENARIOS PRODUCTO DE LAS ENTREVISTAS Y CUESTIONARIOS DE APOYO}

Por la limitante de este trabajo, se decidió seleccionar dos etapas en la presentación de los relatos y respuestas de los entrevistados en distintos puntos de la ciudad donde habitan, para que ellos mismos nos señalen la opinión del lugar donde viven (indicador que nos relaciona con los elementos que dan vida a este concepto y que prácticamente están conectados con las aportaciones de Ramírez y López [2015]), además de sus opiniones sobre lugares agradables y no agradables que reportan en relación a cómo piensan y definen la ciudad donde viven (imaginarios; aportaciones de Silva [2013], Méndez [2015], Fuentes y Rosado [2015] y Moreno [2015]). Desde esta perspectiva y tomando en consideración la relación de las cualidades demográficas de los entrevistados, que en su mayor parte son jóvenes y adultos, los elementos cualitativos que arrojan sus narraciones, como se mencionó anteriormente, cubren dos momentos significativos de acuerdo con el lugar donde habitan: 1) Aquellos cuya proximidad geográfica está relativamente muy cercana entre unos y otros; por ejemplo, los habitantes de Riberas del Bravo (número 4 del mapa 2), así como de Satélite, San 
Pablo e Infonavit Casas Grandes (números 12, 13 y 14 del mapa 2, respectivamente), quienes se orientan a explicar las condiciones de sus lugares en las zonas oriente y sur en Ciudad Juárez, además de representar viviendas de interés social (Riberas del Bravo e Infonavit Casas Grandes) y para grupos de clase media como en San Pablo; y 2) El grupo de colonias en esta parte, que representan un total de trece relatos, se orientan a las zonas del norponiente y suroriente con diversidad en sus condiciones del habitar, sobre todo en el tipo de vivienda edificada; por ejemplo, Villa Colonial (número 2 del mapa 2), Arroyo Colorado y Niños Héroes (números 8 y 11 del mapa 2, ubicadas en el poniente y norponiente, respectivamente); se incluyen también los lugares señalados con los números 1 y 15 de la zona suroriente que corresponden a El Fortín de la Soledad y Parajes de Oriente, respectivamente.

\section{ESCENARIOS Y CONDICIONES EN LA PRIMERA PARTE DE LOS RELATOS}

Esta sección nos permite ubicar siete colonias, una con tres etapas, en donde se seleccionaron nueve relatos que incluyen los siguientes puntos:

1. "Me agradaría que hubiera más seguridad y programas para la juventud. De la ciudad me agrada el parque Central y lo desagradable, las colonias nuevas del suroriente" (Riberas del Bravo Etapa 3; femenino; veintiséis años, tiempo de residencia en Ciudad Juárez: tres años).

2. "Las condiciones del habitar son buenas, de la ciudad me agrada el valle de Juárez por sus áreas verdes y lo que no me agrada es Riberas del Bravo Etapa 8" (Riberas del Bravo Etapa 5; femenino; treinta y cinco años; tiempo de residencia en Ciudad Juárez: diez años).

3. Las condiciones del habitar en su colonia no las específica, pero al momento de responder asienta en forma negativa con su cabeza, lo que indicó que el lugar para él no es agradable. "De la ciudad, el centro, porque se han hecho modificaciones en los lugares del mismo, hay turistas y solo falta limpieza 
de la ciudad; no me agradan Águilas de Zaragoza, el valle de Juárez" (Riberas del Bravo Etapa 4; masculino; cuarenta y tres años; tiempo de residencia en Ciudad Juárez: cuarenta y tres años).

4. Las condiciones del habitar en su colonia las relata como experiencias de no quedarse a vivir en el sitio y de cambiar de lugar. "De la ciudad lo agradable lo representan los centros comerciales por el cine que hay en ellos, y lo desagradable, el centro, por el deterioro que existe en él" (Satélite; masculino; veinte años; tiempo de residencia en Ciudad Juárez: diez años).

5. "El habitar cumple con sus expectativas, pero hay inseguridad en algunas partes; de la ciudad lo agradable es el centro, parque Central, Chamizal, y lo desagradable, Camino Real, Riberas del Bravo" (Satélite; femenino; veintiocho años; tiempo de residencia en Ciudad Juárez: cinco años).

6. "El habitar donde vivo es tranquilo, con seguridad; de la ciudad me agrada la $\mathrm{X}$, porque es de los juarenses, y lo desagradable, las colonias populares y el centro por la inseguridad que hay en ellos" (San Pablo; masculino; veinte años; tiempo de residencia en Ciudad Juárez: dieciocho años).

7. El considera el habitar como un proceso de transición en la ciudad, por lo que espera irse pronto. "Lo agradable de Juárez es la Zona Dorada, porque es estética y se le da mantenimiento; lo desagradable es representado en el centro por su deterioro y condiciones de inseguridad" (San Pablo; masculino; veintiún años; tiempo de residencia en Ciudad Juárez: catorce años).

8. "El habitar en este sitio es bueno, hay condiciones para un buen desarrollo personal, lo agradable de la ciudad no se manifiesta en ningún lugar; en cambio, el centro es un sitio de desagrado por lo feo, inseguro y deteriorado" (Infonavit Casas Grandes; masculino; treinta y dos años; tiempo de residencia en Ciudad Juárez: cuatro años).

9. Espera que su habitar en este lugar cambie y que las condiciones se vuelvan mejores en cuanto a servicios y equipamiento. "Me agrada el centro, porque hay mucho ciclista 
ahí y me gusta practicarlo también; lo desagradable, porque son algo inseguras y segregan a la gente" (Infonavit Casas Grandes; femenino; veinticinco años; tiempo de residencia en Ciudad Juárez: veinticinco años).

En resumen, de estos relatos se descubren elementos importantes en relación con el lugar, la manera en cómo describen el habitar y su relación con el imaginario; por ejemplo, en el caso de Riberas del Bravo (narraciones 1-3), situada en la parte suroriente de la ciudad y señalada con el número 4 en el mapa 2, los contrastes de las respuestas de los tres entrevistados señalan diversos ámbitos en los escenarios de sus colonias: hay desde quien dice que le gusta y que le representa un medio seguro hasta otros que deciden que es un lugar inseguro pero que no les queda de otra; el imaginario para ellos es un futuro de cambio de vivienda a otra colonia o fraccionamiento que les brinde mejores condiciones de vida. En el caso de quienes viven en Satélite (narraciones 4 y 5) ambos entrevistados coinciden en el tipo de ambiente que se ha creado, ya que a pesar de que es una colonia que cuenta con todos los servicios y que es agradable en la ubicación, la inseguridad que ha permeado su estructura la convierte en vulnerable.

El habitar con el significado de la inseguridad en una etapa de transición, se manifiesta particularmente en los relatos de los residentes de San Pablo (narraciones 6 y 7), en donde se encontraron experiencias de los entrevistados de forma emotiva y con una perspectiva en un discurso vivencial dentro de la ciudad, lo cual es importante porque nos lleva a visualizar sus trayectorias en la construcción de un imaginario estable o de posible cambio en uno u otro testimonio. Para los residentes de Infonavit Casas Grandes (narraciones 8 y 9), el ambiente interno de su colonia está también dividido: para uno de ellos representa un habitar seguro, y para otro cuenta con elementos de inseguridad; el imaginario de la ciudad lo direccionan hacia el centro: uno asegura que es feo, desagradable y deteriorado, mientras que para el otro es limpio, con grandes cambios en su equipamiento y, en general, adecuado para visitarlo. 
Procesos espaciales, habitar E IMAGinARIOS EN LOS ESPACiOS URBANOS...

\section{ESCENARIOS Y CONDICIONES EN LA SEGUNDA PARTE DE LOS RELATOS}

Esta sección comprende cinco colonias con catorce relatos de entrevistados que definen las cualidades del lugar donde viven de manera resumida, para comprender la conexión de sus propias vivencias y con el habitar e imaginarios del lugar:

10. El habitar para ella se manifiesta de la siguiente manera: "La cuadra donde vivo es un lugar muy tranquilo. De la ciudad me agrada el parque Central y lo que no me gusta es el centro por la mala fama que tiene de él" (Villa Colonial [Rodas]; femenino; cuarenta y un años; tiempo de residencia en Ciudad Juárez: quince años).

11. "Creo que el lugar donde vivo se puede mejorar, sobre todo en condiciones de limpieza, seguridad y orden. De la ciudad me agradan El Chamizal, el parque Central, los restaurantes y las plazas comerciales, y lo que no me gusta es la parte del centro" (Villa Colonial [Rodas]; masculino; cincuenta y un años; tiempo de residencia en Ciudad Juárez: quince años).

12. "Hay muchas casas deshabitadas y destruidas que hacen ver más feo el lugar y, por tanto, más inseguridad. De la ciudad me gusta el parque Chamizal, el Central, y lo que no me gusta es el centro, por el abandono y deterioro de sus viviendas, sus calles y la existencia de lotes baldíos" (Villa Colonial [Rodas]; femenino; cuarenta y ocho años; tiempo de residencia en Ciudad Juárez: quince años).

13. "Espero ver mi colonia en algún tiempo pronto con todos los servicios necesarios para resolver las carencias y deficiencias que tiene sobre todo en las calles, agua y vivienda. De la ciudad me agrada los parques Chamizal y el Central, y lo que no me gusta es el centro por lo intransitable, el abandono y deterioro de su imagen, y el vandalismo" (Arroyo Colorado; femenino; treinta y dos años; tiempo de residencia en Ciudad Juárez: dieciséis años).

14. "La colonia, a pesar de ser desértica, es un lugar tranquilo, a pesar de la violencia que sufrimos constantemente, pero ya 
contamos con una gasolinera, un Smart, una universidad, preparatoria, secundaria, Oxxo, centro comunitario, entre otras cosas. De la ciudad me agrada el centro y, en general, toda la ciudad; lo que no me agrada de ella es su transporte público, viejo, obsoleto, con unidades chatarra, en pocas palabras, pésimo" (Arroyo Colorado; masculino; cincuenta y siete años; tiempo de residencia en Ciudad Juárez: treinta años).

15. "Las condiciones y el lugar donde habito son muy buenas y me agradan los espacios donde me desenvuelvo. De la ciudad me agradan los parques, en especial El Chamizal, el centro; lo que no me gusta es su violencia e inseguridad" (Arroyo Colorado; masculino; cincuenta y seis años; tiempo de residencia en Ciudad Juárez: treinta y dos años).

16. "El lugar es un muy sitio de vivir la ciudad, gracias a Dios no me ha pasado nada malo y estoy contenta. De la ciudad lo que más me agrada es Catedral y lo que no es Anapra, el centro y el abandono de casas que hay en toda la ciudad" (Niños Héroes; femenino; veinticinco años; tiempo de residencia en Ciudad Juárez: trece años).

17. "Falta pavimentación en algunas calles, hay terrenos baldíos y tienen muchos problemas en su mantenimiento, atraviesa un arroyo en una de las calles y cuando llueve se junta mucha basura. De la ciudad me agrada los parques Central y El Chamizal, y en general de la ciudad no hay ningún sitio que me disguste" (Niños Héroes; femenino; treinta y un años; tiempo de residencia en Ciudad Juárez: treinta y un años).

18. "Considero que en mi lugar debe mejorarse la seguridad, ya que en la misma hay venta de drogas a niños y adolescentes, eso es preocupante. De la ciudad me agradan sus parques y lo que no me gusta es el centro" (Niños Héroes; masculino; sesenta años; tiempo de residencia en Ciudad Juárez: sesenta años).

19. "Está bonito, pero hay muchos perros y la basura que estos hacen. De la ciudad me agradan los centros comerciales, y lo que me disgusta es ir al centro, no voy para allá" (El Fortín de la Soledad; masculino; cuarenta años; tiempo de residencia en Ciudad Juárez: diez años). 
20. "Es un lugar muy apacible, son casas muy buenas y los espacios cumplen con lo requerido, de repente hay mucha basura y eso trae enfermedades. De la ciudad me agrada el centro, aunque ya no es lo que fue" (El Fortín de la Soledad; masculino; sesenta y dos años; tiempo de residencia en Ciudad Juárez: diez años).

21. "El lugar donde vivo es muy céntrico y no se batalla para andar aquí, pero he encontrado a vecinos invasores y la gente que viene a ensuciar el parque. De la ciudad está suave por el rumbo de la Ejército Nacional y lo que no me agrada es el centro, ni aunque me paguen" (El Fortín de la Soledad; masculino; cincuenta y tres años; tiempo de residencia en Ciudad Juárez: seis años).

22. "Le falta vigilancia, de protección, porque lo que busca uno es vivir en paz. De la ciudad, El Chamizal y lo que no es de mi gusto es el bulevar Zaragoza" (Parajes de Oriente; masculino; cuarenta y un años; tiempo de residencia en Ciudad Juárez: diecinueve años).

23. "El lugar donde vivo es un ambiente muy agradable, me imagino como un lugar más limpio, del que es hoy, sigo viendo algunos elementos de suciedad y abandono. De la ciudad no hay ningún lugar que me gusta y de los que me desagradan son las colonias viejas, porque no hay mantenimiento" (Parajes de Oriente; masculino; veinte años; tiempo de residencia en Ciudad Juárez: diez años).

24. "Es un lugar muy tranquilo en ocasiones, ya que la mayor parte del tiempo la paso en mi trabajo, solo espero que cuando no me encuentre en mi casa no se metan a robar. De la ciudad me agrada el parque Borunda, porque ahí he realizado varias citas y lo que me agrada de la misma son algunas partes del centro, ya que no las frecuento constantemente y cuando voy me he perdido" (Granjas de Chapultepec; masculino; veinticinco años; tiempo de residencia en Ciudad Juárez: catorce años).

25. "Es un lugar seguro pero lleno de carencias y las perspectivas del habitar en la colonia las concibo como bajas, por falta de cosas como alumbrado público, vandalismo y carencias eco- 
nómicas. De la ciudad me agrada los parques Borunda, Central y sitios recreativos para la familia. Y lo que no me gusta son los centros nocturnos por su inseguridad y las colonias periféricas" (Granjas de Chapultepec; masculino; veintidós años; tiempo de residencia en Ciudad Juárez: veintidós años).

En esta segunda parte los habitantes entrevistados muestran distintas maneras de concebir el lugar donde viven; su orientación es concebir la vivienda, en particular donde se desenvuelven, como un espacio de protección y seguridad. En cuanto al entorno próximo y donde construyen los imaginarios, los parques El Chamizal, Central y Borunda cumplen un papel importante en la construcción de un bienestar sólido para la recreación y entretenimiento a nivel individual y familiar, donde las interacciones colectivas son parte fundamental de la construcción del imaginario urbano de esta ciudad fronteriza.

\section{REFLEXIONES FINALES}

Los relatos y las experiencias de los actores son parte de las visiones fundamentales que la cotidianidad impregna en ello: lugares, símbolos, usos y prácticas forman parte de ese mosaico que se genera en los distintos puntos del territorio de Ciudad Juárez.

La experiencia de vivir Ciudad Juárez presenta vaivenes simbólicos y emblemáticos en las definiciones de sus residentes, en donde manifiestan las intenciones de mejorar las condiciones de su entorno inmediato y próximo, ya que su vivienda representa una gran oportunidad de mejorar las cualidades que planearon al momento de decidir permanecer en su colonia o fraccionamiento, para dar una mejor imagen a su lugar y establecer un habitar permanente en la ciudad. Por tanto, hay una apropiación del espacio donde se asentaron y de las concepciones que realizan al habitar en un sector determinado; además, se fortalece la idea del imaginario del espacio cotidiano que les permite identificar algunas condiciones o hechos específicos en cada rincón relatado por ellos durante las entrevistas. 
Los imaginarios son una parte sustancial que ayuda a la comprensión de esas experiencias que los residentes de Ciudad Juárez hacen de su medio. La construcción de significados es parte de esos momentos en los que ayudan a comprender la relación con el espacio urbano, donde se cobijan las acciones cotidianas. El espacio forma parte de esa intersección con el habitar, donde se tejen interacciones con el vecino, el compañero de trabajo, los amigos, entre otros actores.

\section{BIBLIOGRAFÍA}

Camacho, M. (2002). Hacia una teoría del espacio: reflexión fenomenológica sobre el ambiente. Puebla. Universidad Iberoamericana de Puebla, Benemérita Universidad Autónoma de Puebla. Félix, J. (2016). Entre asentamientos irregulares y desarrollos urbanos legales: la construcción social del espacio residencial en Tijuana. Tijuana: El Colegio de la Frontera Norte.

Fuentes, J., \& Rosado, D. (2015). Imaginando Mérida, Yucatán: imaginarios urbanos de pobladores locales, nacionales y extranjeros. En E. Méndez, H. Roldán, \& J. Acosta (Coords.), Ciudades imaginadas en el encuentro turístico (pp. 83-101). México: Universidad Autónoma de Sinaloa/Juan Pablos Editor. García, N. (1999). Imaginarios urbanos. Buenos Aires: Eudeba. Licona, E. (2007). Habitar y significar la ciudad. México: Consejo Nacional de Ciencia y Tecnología/Universidad Autónoma Metropolitana.

Limas, M. (2010). Geografía de la pobreza en Ciudad Juárez: una perspectiva de género. Ciudad Juárez: Universidad Autónoma de Ciudad Juárez.

Macareño, G., \& Roldán, H. (2015). Urbanización multicausal y sustentabilidad del desarrollo: nuevas tendencias para entender lo urbano. En E. Méndez, H. Roldán, \& J. Acosta (Coords.), Ciudades imaginadas en el encuentro turístico (pp. 143-150). México: Universidad Autónoma de Sinaloa/Juan Pablos Editor. Méndez, E. (2015). Lugar, orden y narración, o cuando Álamos nació en un portal. En E. Méndez, H. Roldán, \& J. Acosta 
(Coords.), Ciudades imaginadas en el encuentro turístico (pp. 25-44). México: Universidad Autónoma de Sinaloa/Juan Pablos Editor.

Moreno, R. (2015). Entre la inseguridad y seguridad urbana: visiones del habitar, espacio social y los imaginarios en Ciudad Juárez. En A. Aguilar, \& I. Escamilla (Coords.), Segregación urbana y espacios de exclusión: ejemplos de México y América Latina (pp. 257-284). México: Universidad Nacional Autónoma de México/Porrúa.

Peña, L. (2015) Estudio y propuesta de movilidad interbarrial del Plan Estratégico Vecinal (Pev) de Paraje del Sur, Ciudad Juárez. En A. Aguilar, \& I. Escamilla (Coords.), Segregación urbana y espacios de exclusión: ejemplos de México y América Latina (pp. 241-256). México: Universidad Nacional Autónoma de México/Porrúa.

Prieto, E. (2011). La arquitectura de la ciudad global: redes, nolugares, naturaleza. Madrid: Biblioteca Nueva.

Ramírez, B., \& López, L. (2015). Espacio, paisaje, región, territorio y lugar: la diversidad en el pensamiento contemporáneo. México: Universidad Nacional Autónoma de México/Universidad Autónoma Metropolitana-Unidad Xochimilco.

Roncayolo, M. (1988). La ciudad (Col. Estética). Buenos Aires: Paidós.

Silva, A. (2013). Imaginarios, el asombro social. Bogotá: Universidad Externado de Colombia.

Torres, E. (2010). La ciudad desde los imaginarios urbanos. La civdad viva. Recuperado el 22 de septiembre de 2017, de http:// www.la ciudadviva.org/01 